\title{
Utilización de un suplemento mineral orgánico en la alimentación de vacas lecheras Holstein durante la etapa de transición
}

\author{
Use of an organic mineral supplement in Holstein dairy cow feed during the transition stage
}

\author{
Miriam Fernández S. ${ }^{1}$; José Almeyda M. ${ }^{2}$; Carlos Gómez B. ${ }^{3}$
}

\begin{abstract}
Resumen
El objetivo del estudio fue evaluar el efecto de un suplemento mineral orgánico en la alimentación de vacas lecheras sobre la producción y calidad de leche, para lo cual se utilizaron 27 vacas de raza Holstein, distribuidas de manera aleatoria en dos grupos: experimental (T1) y testigo (T2), con 14 y 13 animales, respectivamente. Las vacas en evaluación fueron animales de segundo y tercer parto. La alimentación se basó en una ración compuesta por broza de espárrago como forraje, concentrado para vacas en producción y complementado con residuos de turión y alcachofa. El suplemento mineral orgánico fue suministrado individualmente en proporciones de $150 \mathrm{~g} /$ día en el periodo pre parto (tres semanas) y $214 \mathrm{~g} /$ día en el postparto (cuatro semanas). Las vacas fueron ordeñadas tres veces al día. Para la evaluación, se controló la producción de leche semanalmente y se sacaron muestras del mismo para los análisis de laboratorio de proteína, grasa y conteo de células somáticas. El periodo de evaluación de los datos comprendió desde el día 80 al 101 de lactación. Los resultados fueron analizados a través del diseño estadístico completamente al azar y se utilizó la prueba t de Student para evaluar la comparación de medias, con un nivel de significación de $\mathrm{P} \leq 0,05$. Los resultados mostraron los siguientes valores: producción de leche 34,95 y $33,33 \mathrm{~kg} / \mathrm{vaca} /$ día, grasa en la leche 2,87 y 2,81\% y conteo de células somáticas 267.500 y 365.000 células $/ \mathrm{ml}$ para las vacas del grupo experimental y testigo, respectivamente, no encontrándose diferencias estadísticas entre ellos y para la proteína en la leche se encontró niveles de 2,95 y 2,70 \% para el grupo experimental y testigo, respectivamente, que resultaron estadísticamente significativos entre ellos, es por esta razón que se recomienda el uso del suplemento mineral orgánico para incrementar el nivel de proteína en leche.
\end{abstract}

Palabras clave: calidad de leche; producción de leche; suplemento mineral.

\begin{abstract}
The objective of this study was to evaluate the use of an organic mineral supplement in the feeding of dairy cows on milk yield and milk quality, for this purpose we used 27 Holstein cows; distributed randomly in two groups: an experimental group (T1) and a control group (T2), with 14 and 13 cows respectively. The cows evaluated were from second and third partum. The feeding was based on a food portion composed of forage (brush asparagus), concentrate for cows in production and supplemented with asparagus shoots residues and artichoke. The organic mineral supplement was supplied individually in proportions of $150 \mathrm{~g}$ prepartum (three weeks) and $214 \mathrm{~g}$ postpartum (four weeks). Cows were milked three times a day. For the evaluation milk yield was controlled weekly and samples were taken to analyse protein and fat content, as well as somatic cells count. The evaluation period of the data was from day 80 to day 101 of lactation. The results were analysed using a completely randomized statistical design and student's t proof was used to evaluate the comparison of means, with a significance level of $(\mathrm{P} \leq 0,05)$. The results showed the following values for cows on the experimental group and control group respectively: milk yield (34,95 vs. 33,33kg/cow/day), percentage fat (2, $87 \%$ vs. $2,81 \%$ ), and somatic cells count $(267.500$ cells $/ \mathrm{ml}$ vs. 365.000 cells $/ \mathrm{ml})$. There was no statistic difference between the treatments. On the other hand for protein content in the milk we found levels of $2,95 \%$ vs $2,70 \%$ for the experimental and control groups respectively which were statistically significant among them. For this reason the use of organic mineral supplement to increase the level of protein in milk is recommended.
\end{abstract}

Keywords: milk quality; milk yield; mineral supplement.

\section{Introducción}

La producción de leche en el Perú es una de las actividades económicas con mayores posibilidades de desarrollo, debido a la existencia de una amplia demanda insatisfecha de leche. Es por ello que las ganaderías dedicadas a la producción de leche deben tratar de ser más eficientes $\mathrm{y}$, por ende, lograr mejores niveles de producción y consecuentemente mayor rentabilidad. En los establos de crianza intensiva que disponen de vacas de alto potencial genético, se puede maximizar el potencial productivo, 
para lo cual es indispensable complementar las raciones alimenticias con la incorporación de minerales y vitaminas, para así ayudar al animal a ser más eficiente en aprovechar los nutrientes de la ración, así como para mejorar su salud. Por estas razones, actualmente hay mucho interés por el uso de minerales de origen orgánico en las raciones alimenticias debido a su mayor biodisponibilidad para el animal, el mismo que de acuerdo a las recomendaciones de los especialistas contribuye a la mejora del rendimiento de la producción y calidad de la leche.

Así, Nocek et al. (2006) evaluaron el suministro de minerales en la ración de vacas lecheras determinando que los animales que consumieron raciones con minerales de origen orgánico mejoraron en su rendimiento de leche, así como los porcentajes de grasa y proteína en la leche, comparados con aquellos que fueron suplementadas con minerales inorgánicas.

Igualmente, Kellogg et al. (2004) evaluaron el efecto del complejo mineral orgánico zinc-metionina en vacas en producción determinando que los animales que recibieron el complejo mineral indicado produjeron más leche comparados al grupo control (7,06 \% más); los autores indicaron que el hecho se debe, probablemente, a la mejora en la salud de la ubre. Sin embargo, los mismos autores determinaron que los porcentajes de grasa y proteína en la leche no fueron afectados. Por otro lado, Uchida et al. (2001), al evaluar la inclusión de minerales inorgánicos con complejos de aminoácidos desde el parto hasta el primer servicio de empadre, encontraron que el nivel de producción de leche no fue afectado.

Respecto al efecto de los minerales en el conteo de células somáticas, Dibley, 2001, mencionado por Kellogg et al. (2004) afirma que el zinc juega un papel integral en la función inmune, impactando así en la disminución del nivel de células somáticas en la glándula mamaria. Al evaluar su uso, encontraron que las vacas que recibieron de 360 a $400 \mathrm{mg} / \mathrm{animal}$ de zinc, sufrieron una reducción de hasta 42,6\% de las células somáticas en la leche (de 298.000 bajó a 171.000 células/ml).

El objetivo del presente estudio fue evaluar el efecto de la utilización de un suplemento mineral orgánico en la producción y calidad de la leche, a través de los porcentajes de grasa, proteína y conteo de células somáticas.

\section{Materiales y métodos}

El presente trabajo de investigación se ejecutó en el establo La Joya, ubicado en la provincia de Trujillo, región La Libertad, a una altitud promedio de $85 \mathrm{msnm}$, con un clima semicálido y temperaturas que varían desde los $15,8{ }^{\circ} \mathrm{C}$ hasta los $22,7^{\circ} \mathrm{C}$. El periodo de ejecución fue de mayo a diciembre del 2004. Para realizar el ensayo se utilizaron 27 vacas de raza Holstien de segundo y tercer parto, las mismas que fueron distribuidas de manera aleatoria en dos grupos:14 para el grupo experimental (T1) y 13 para el grupo control (T2). Los tratamientos se establecieron de la siguiente manera: Grupo experimental (T1): Dieta basal correspondiente a la etapa preparto y postparto más suplemento mineral orgánico y Grupo control (T2): Dieta

Tabla 1. Suministro de las dietas basales de base fresca y seca

\begin{tabular}{lcccc}
\hline \multirow{2}{*}{ INSUMO } & \multicolumn{2}{c}{ VACAS SECAS } & \multicolumn{2}{c}{ VACAS EN PRODUCCIÓN } \\
& Base Fresca & Base Seca & Base Fresca & Base Seca \\
\hline Concentrado kg/día & 4,00 & 3,33 & 11,00 & 9,16 \\
Broza verde espárrago kg/día & 10,00 & 2,97 & 30,00 & 8,91 \\
Alcachofa sancochada kg/día & 30,00 & 3,71 & 30,00 & 3,71 \\
Turión de espárrago kg/día & 0,00 & 0,00 & 20,00 & 1,33 \\
Total consumo kg/día & 49,00 & 10,01 & 91,00 & 23,11 \\
\hline
\end{tabular}

Fuente: Elaboración propia.

Tabla 2. Composición porcentual del concentrado utilizado en el experimento (base fresca)

\begin{tabular}{|c|c|c|}
\hline INSUMO & VACA SECA $(\%)$ & VACAS PRODUCCIÓN (\%) \\
\hline Pepa algodón & 14,10 & 30,00 \\
\hline Maíz molido & 40,00 & 30,00 \\
\hline Melaza & 23,00 & 18,30 \\
\hline Algarrobo & 17,00 & 9,70 \\
\hline Harina pescado $1 \mathrm{ra}$. & 3,00 & 0,00 \\
\hline Subproducto de trigo & 0,00 & 8,90 \\
\hline Sal & 0,60 & 0,60 \\
\hline Urea & 0,84 & 1,00 \\
\hline Carbonato de calcio & 1,20 & 1,20 \\
\hline PREMIX (Mikromix Vacunos Lactación) & 0,25 & 0,20 \\
\hline TOTAL & 99,9 & 99,9 \\
\hline
\end{tabular}

Fuente: Establo "La Joya". 
basal correspondiente a la etapa preparto y postparto sin suplemento mineral orgánico.

La ración durante la etapa experimental contempló la utilización de concentrado, forraje y suplemento mineral orgánico (sólo en el grupo experimental). Las raciones basales de base fresca y seca suministradas a los dos grupos de vacas se muestran en la Tabla 1 .

El suministro de concentrado fue de acuerdo al programa de alimentación del establo para los dos tratamientos. La composición porcentual del concentrado utilizado en el experimento se muestra en la Tabla 2 y el contenido nutricional en la Tabla 3.

En cuanto al valor nutricional de la broza de espárrago se determinó los siguientes valores: proteína: $12,1 \%$, NDT: $59,6 \%$ y EN1 :1,20 Mcal/kg y para los subproductos turión de espárrago y residuo de alcachofa los valores fueron: $30,1 \mathrm{y}$

18,2 \% de proteína; ENl: 1,7 y 1,5 Mcal/kg y NDT: 73,8 y $68,0 \%$, respectivamente. El suministro del suplemento mineral orgánico se suministró en forma individual a cada vaca para asegurar su consumo total. El periodo de suministro del suplemento fue en la etapa de transición de la vaca, es decir cuatro semanas antes del parto y tres semanas postparto. El consumo del suplemento mineral orgánico antes del parto fue de 150 gramos por animal por día y de 214 gramos postparto por animal por día. En cada etapa de preparto y postparto consumieron $4,5 \mathrm{~kg}$. Al final del periodo experimental mencionado, la vaca consumió un total de $9 \mathrm{~kg}$ del suplemento.

En la Tabla 4 se presenta la composición química del suplemento mineral orgánico.

Dentro del manejo habitual del establo se realizaron tres ordeños al día: $4 \mathrm{am} ; 12 \mathrm{~m}$ y $8 \mathrm{pm}$. La toma de datos para la evaluación correspondiente consideró el consumo del suplemento mineral orgánico y rendimiento de leche. En lo que se refiere a las evaluaciones del consumo del suplemento mineral orgánico fueron de forma individual durante el periodo de transición. Por otro lado, las evaluaciones del rendimiento de leche se realizaron semanalmente desde el día 10 de producción para tener una referencia previa al periodo específico de evaluación que comprendió desde el día 80 hasta los 101 días de lactación.

Tabla 3. Contenido nutricional de los concentrados utilizados en el experimento

\begin{tabular}{lcccc}
\hline \multirow{2}{*}{ NUTRIENTES } & \multicolumn{2}{c}{ VACA SECA } & \multicolumn{2}{c}{ VACA EN PRODUCCIÓN } \\
& Base Fresca & Base Seca & Base Fresca & Base Seca \\
\hline Humedad \% & 20,81 & 0,00 & 16,71 & 0,00 \\
Materia seca \% & 79,19 & 100,00 & 83,29 & 100,00 \\
En (l) Mcal/kg * & 1,72 & --- & 1,79 & --- \\
Proteína cruda \% & 10,33 & 13,04 & 16,12 & 19,35 \\
Extracto etéreo \% & 6,94 & 8,76 & 8,24 & 9,89 \\
Fibra cruda \% & 4,61 & 5,82 & 8,50 & 10,21 \\
Ceniza \% & 6,10 & 7,70 & 5,82 & 6,99 \\
Eln \% & 5121 & 64,67 & 44,61 & 53,56 \\
Calcio \% & $0,71 *$ & 0,90 & 0,72 & 0,86 \\
Fósforo \% & $0,37 *$ & 0,47 & 0,42 & 0,50 \\
\hline
\end{tabular}

* Valores estimados.

Fuente: Laboratorio de Evaluación Nutricional de los Alimentos de la UNALM.

Tabla 4. Composición química del suplemento mineral orgánico

\begin{tabular}{lc}
\hline \multicolumn{1}{c}{ NUTRIENTE } & BASE FRESCA \\
\hline Humedad \% & 15,03 \\
Materia seca \% & 84,97 \\
Proteína total \% & 9,89 \\
Extracto etéreo \% & 0,49 \\
Fibra cruda \% & 7,53 \\
Ceniza \% & 28,49 \\
Extracto libre de N \% & 38,57 \\
Fósforo \% & 0,36 \\
Hierro \% & 0,15 \\
\hline
\end{tabular}

Fuente: Laboratorio Análisis de los Alimentos UNALM. 
Los análisis proximales del concentrado, forraje, subproductos y suplemento mineral orgánico se realizaron en el Laboratorio de Evaluación Nutricional de los Alimentos de la Universidad Nacional Agraria La Molina. En cuanto a los análisis de grasa, proteína y conteo de células somáticas de la leche, estos se efectuaron en el laboratorio de la empresa Nestlé Perú, utilizando el equipo Milkoscan para los análisis de grasa y proteína y el contador electrónico Fossomatic para el conteo de células somáticas.

Para analizar los resultados se utilizó el diseño completamente al azar y la prueba t de student (Calzada, 1981) para la comparación de medias. Con respecto a los porcentajes de grasa y proteína, se realizaron previamente las transformaciones angulares con el arcoseno de los valores (Calzada, 1981). Debido al número de variables independientes se utilizó el programa estadístico S.A.S. El modelo estadístico fue el siguiente:

$\mathrm{Y}_{\mathrm{ij}}=\mathrm{m}+\mathrm{t}_{\mathrm{i}}+\mathrm{e}_{\mathrm{ij}}$

$\mathrm{i}=1, . . \mathrm{t}(\mathrm{t}=2)$

$\mathrm{j}=1, . . \mathrm{r}(\mathrm{r}=14$ experimental y $\mathrm{r}=13$ control $)$

Donde:

$\mathrm{Y}_{\mathrm{ij}}=$ La producción de leche en $\mathrm{kg}$, porcentaje de grasa, porcentaje de proteína y conteo de células somáticas observados con el i-ésimo nivel de suplemento mineral en la j-ésima vaca.

$\mathrm{m}$ = Promedio de producción de leche en $\mathrm{kg}$, porcentaje de grasa, porcentaje de proteína y conteo de células somáticas. $\mathrm{t}_{\mathrm{i}}=$ Efecto del $\mathrm{i}$-ésimo nivel de suplemento mineral.

$\mathrm{e}_{\mathrm{ij}}=$ Efecto del error experimental observado en la j-ésima vaca, a la que se le suministró al i-ésimo nivel de suplemento mineral.

\section{Resultados y discusión}

Efecto de la suplementación mineral orgánica sobre la producción de leche

En la Tabla 5 se observa la producción de leche promedio de las vacas alimentadas con raciones con y sin suplemento mineral. Al realizar la prueba de significancia de los promedios, los resultados indican que no hay diferencias estadísticas entre los tratamientos. Esta similitud en los valores encontrados, posiblemente se debe a que en la ración testigo los requerimientos nutricionales de minerales y vitaminas fueron cubiertos por la ración proporcionada ya que contenía una premezcla mineral en su composición. Los resultados encontrados en el presente trabajo fueron similares a los obtenidos por Uchida et al. (2001), quienes reemplazaron fuentes inorgánicas de minerales por complejos de minerales orgánicos y el nivel de producción de leche no fue afectado. Sin embargo, fueron diferentes a los reportados por Kellogg et al. (2004) y Nocek et al. (2006) quienes trabajaron con minerales orgánicos encontrando una mayor producción de leche en los tratamientos que incluían minerales orgánicos. Específicamente Kellogg et al. (2004), al evaluar el efecto del mineral orgánico zinc- metionina, obtuvieron incrementos en la producción de leche de 7,06 \% comparados con los grupos testigo; los investigadores señalaron que el aumento se debe, posiblemente, a la mejora en la salud de la ubre.

En la Tabla 6 se presentan los rendimientos semanales por tratamiento, obtenidos durante el periodo de evaluación.

En la Fig. 1 se representa la producción de leche de cada uno de los tratamientos.

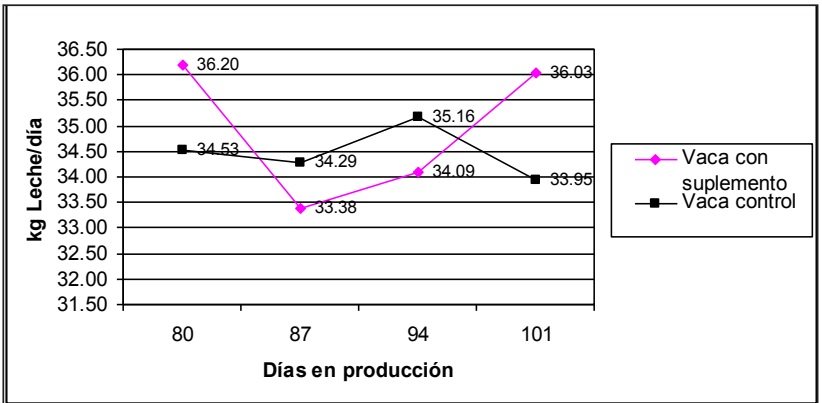

Figura 1. Producción de leche desde el día 80 al 101 de lactación

En la Figura se observa que en el día 80 se empezó con una producción promedio de $36,20 \mathrm{~kg} / \mathrm{vaca} /$ día para el tratamiento experimental versus $34,53 \mathrm{~kg} / \mathrm{vaca} /$ día para el tratamiento testigo, pero con el transcurrir de los días se observó un declive de la curva de producción del

Tabla 5. Promedios de producción de leche de los tratamientos

\begin{tabular}{lcc}
\hline \multicolumn{1}{c}{ Tratamientos } & Promedio & $\begin{array}{c}\text { Coeficiente de } \\
\text { variación (\%) }\end{array}$ \\
\hline T1: Vacas con suplemento mineral orgánico (kg/vaca/día) & $34,95 \pm 0,63^{\mathrm{a}}$ & 1,80 \\
T2: Vacas control (kg/vaca/día) & $34,46 \pm 0,25^{\mathrm{a}}$ & 0,74
\end{tabular}

(a) Letras iguales significa que no existe diferencia estadística significativa $(\mathrm{P}>0,05)$.

Tabla 6. Producción de leche desde el día 80 a 101 de lactación

\begin{tabular}{lcrrc}
\hline \multicolumn{1}{c}{ Tratamientos } & \multicolumn{4}{c}{ Días de evaluación } \\
& 80 & 87 & 94 & 101 \\
\hline T1: Vacas con suplemento mineral orgánico (kg/vaca/día) & 36,20 & 33,38 & 34,09 & 36,03 \\
T2: Vacas control (kg/vaca/día) & 34,53 & 34,29 & 35,16 & 33,95 \\
\hline
\end{tabular}

Fuente: Elaboración propia. 
tratamiento experimental que llegó así a un valor de 33,38 $\mathrm{kg} / \mathrm{vaca} /$ día en el día 87 . En contraposición, la curva de producción del tratamiento testigo también presentó una ligera disminución que llegó a un valor de 34,29 kg/vaca/ día; aun habiendo disminuido, este valor es superior al del grupo experimental. Esto se debe, posiblemente, a una disminución en el consumo de la ración alimenticia, lo cual pudo afectar el nivel de energía disponible para la producción de leche.

Después del día 87, se observaron incrementos en ambas curvas de producción, llegando a valores de 34,09 kg/vaca/ día para el tratamiento experimental y $35,16 \mathrm{~kg} / \mathrm{vaca} /$ día para el tratamiento testigo. Para la siguiente semana se observó que la curva del tratamiento experimental continuó en ascenso llegando finalmente a un valor de $36,03 \mathrm{~kg} /$ vaca/día, ocurriendo lo contrario en el tratamiento testigo, pues se observó la disminución de la producción que llegó a un valor de 33,95 kg/vaca/día. Esta variación en el grupo experimental pudo deberse al efecto del suplemento mineral orgánico en el aprovechamiento de la energía de la dieta.

Efectos de la suplementación mineral orgánica sobre el porcentaje de grasa en la leche

En la Tabla 7 se presentan los promedios de porcentaje de grasa en la leche de las vacas de cada uno de los tratamientos evaluados.

De acuerdo con la prueba de significancia de los promedios, no se encontraron diferencias estadísticas entre ambos tratamientos, pues se obtuvo un valor de 2,87\% para el grupo experimental (T1) y 3,01\% para el grupo control (T2). Esta respuesta, aparentemente, puede deberse a que los niveles de fibra efectiva absoluta contenida en la ración proporcionada a las vacas de ambos grupos fueron similares, obteniéndose así una equivalente proporción molar de ácido acético /ácido propiónico a nivel ruminal en ambos tratamientos.

Estos resultados coinciden con los encontrados por Kellogg et al. (2004) quienes, al utilizar fuentes orgánicas en la suplementación de minerales en vacas lecheras, no encontraron un efecto significativo en el contenido de grasa en la leche. Sin embargo, los resultados del estudio fueron diferentes a lo reportado por Nocek et al. (2006) quienes, al evaluar el uso de minerales orgánicos, encontraron que las vacas del grupo experimental reportaron un mayor porcentaje de grasa en la leche frente a las del grupo testigo que consumieron en su ración minerales de fuentes inorgánicas.

En la Tabla 8 se muestra los porcentajes de grasa semanal en la leche durante el periodo de evaluación.

En la Fig. 2 se representa los porcentajes de grasa de la leche de cada uno de los tratamientos.

En la Figura se observa que la pendiente de la curva de porcentaje de grasa del tratamiento experimental fue constante, aproximándose a una línea horizontal, salvo en el tramo comprendido entre los días 94 y el 101 de lactación, en la que tuvo una ligera disminución. En cuanto

Tabla 7. Promedios de porcentaje de grasa de los tratamientos

\begin{tabular}{lcc}
\hline \multicolumn{1}{c}{ Tratamientos } & Promedio & $\begin{array}{c}\text { Coeficiente de } \\
\text { variación }(\%)\end{array}$ \\
\hline T1: Vacas con suplemento mineral orgánico $(\%)$ & $2,87 \pm 0,04^{\mathrm{a}}$ & 1,42 \\
T2: Vacas control (\%) & $3,01 \pm 0,25^{\mathrm{a}}$ & 8,41 \\
\hline
\end{tabular}

${ }^{a}$ Letras iguales significa que no existe diferencia estadística significativa.

Tabla 8. Porcentaje de grasa en la leche desde el día 80 hasta 101 de lactación

\begin{tabular}{lcccc}
\hline \multirow{2}{*}{ Tratamientos } & \multicolumn{3}{c}{ Días de evaluación } \\
& 80 & 87 & 94 & 101 \\
\hline T1: Vacas con suplemento mineral orgánico (\%) & 2,96 & 2,99 & 2,83 & 2,84 \\
T2: Vacas control (\%) & 2,86 & 3,22 & 2,24 & 3,34 \\
Fuente: Elaboración propia. & \multicolumn{4}{l}{} \\
\end{tabular}

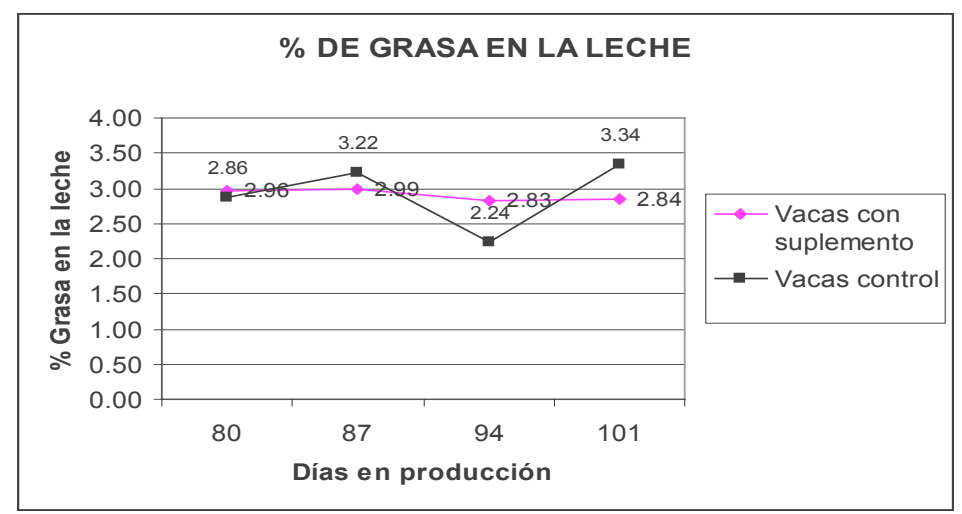

Figura 2. Porcentaje de grasa en la leche desde el día 80 a 101 de lactación 
a la curva de porcentaje de grasa del tratamiento testigo, al día 80 presentó un valor de $2,86 \%$ comparado con $2,96 \%$ del tratamiento experimental; luego tuvo un ascenso al día 87 de $3,22 \%$, pero en la siguiente semana se observó una disminución llegando a un valor 2,24 \%. Finalmente, el día 101 terminó con un valor de 3,34\%.

Al observar los promedios de porcentaje de ambos tratamientos, se aprecia que el valor numérico del tratamiento testigo $(3,01 \%)$ se aproxima más que el tratamiento experimental $(2,87 \%)$ a los estándares de las especificaciones técnicas de la leche cruda exigidas por el INDECOPI (1998), según el cual el componente de materia grasa de la leche debe tener un valor mínimo de 3,20\%.

Efectos de la suplementación mineral orgánica sobre el porcentaje de proteína en la leche.

En la Tabla 9 se presentan los promedios de porcentaje de proteína contenida en la leche observados en las vacas de ambos tratamientos.

De acuerdo con la prueba de significancia se encontraron diferencias estadísticas significativas entre los tratamientos con porcentajes promedios de $2,95 \%$ para el grupo con suplemento mineral (T1) frente a un 2,70\% para el grupo control (T2). Esta diferencia favorable en el grupo experimental, posiblemente, se deba a que el suplemento mineral derivado de algas influyó en mejorar la eficiencia de la utilización de la energía en la ración para la síntesis de proteína.

Estos resultados coinciden con los obtenidos por Nocek et al. (2006), quienes utilizaron minerales orgánicos versus inorgánicos en vacas lecheras; pero, a su vez, existen estudios como los de Kellogg et al. (2004) que no confirman este efecto favorable en el contenido de la proteína al utilizar minerales orgánicos en raciones para vacas lecheras.

En la Tabla 10 se muestran los rendimientos de los porcentajes de proteína en la leche durante el periodo de evaluación.

En la Fig. 3 se muestra la representación de los porcentajes de proteína desde el día 80 al día 101 de lactación de cada uno de los grupos experimentales.

En la Fig. 3 se aprecia que la curva de porcentaje de proteína del tratamiento experimental inicia con un valor de 3,00\% en el día 80, luego se observa una disminución, llegando a un valor de $2,82 \%$ al día 87 . De allí en adelante hasta el final del periodo de evaluación, se aprecia un incremento de la pendiente de esta curva, llegando a un valor máximo de 3,05\% en el día 101 días de lactación.

En cuanto a la curva de porcentaje de proteína del tratamiento testigo, no llegó a intersectar en ningún punto a la del tratamiento experimental, observándose un

Tabla 9. Promedios de porcentaje de proteína de los tratamientos

\begin{tabular}{lcc}
\multicolumn{1}{c}{ Tratamientos } & Promedio & $\begin{array}{c}\text { Coeficiente de } \\
\text { variación }(\%)\end{array}$ \\
\hline T1: Vacas con suplemento mineral orgánico $(\%)$ & $2,95 \pm 0,05^{\mathrm{a}}$ & 1,56 \\
T2: Vacas control (\%) & $2,70 \pm 0,07^{\mathrm{b}}$ & 2,65 \\
\hline
\end{tabular}

a,b Letras diferentes significa que existe diferencia estadística.

Tabla 10. Porcentaje de proteína en la leche desde el día 80 a 101 de lactación

\begin{tabular}{lcccc}
\hline \multirow{2}{*}{ Tratamientos } & \multicolumn{4}{c}{ Días de evaluación } \\
& 80 & 87 & 94 & 101 \\
\hline T1: Vacas con suplemento mineral orgánico (\%) & 3,00 & 2,82 & 2,90 & 3,05 \\
T2: Vacas control (\%) & 2,52 & 2,68 & 2,58 & 2,82 \\
\hline
\end{tabular}

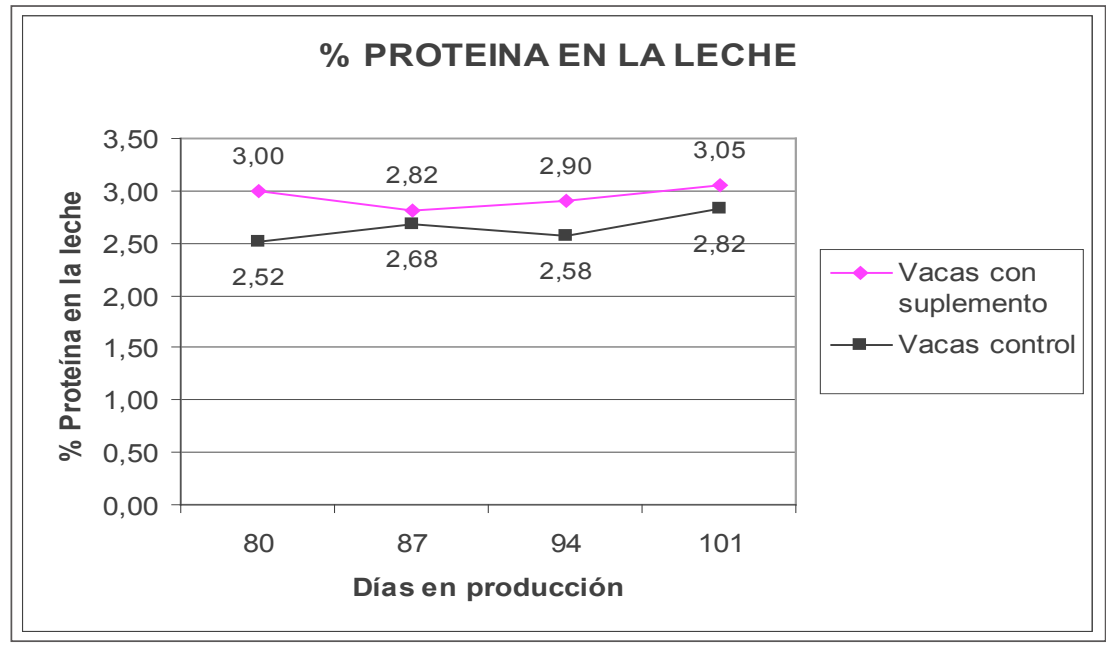

Figura 3. Porcentaje de proteína desde el día 80 al 101 de lactación 
Tabla 11. Promedios del conteo de células somáticas de los tratamientos

\begin{tabular}{lcc}
\multicolumn{1}{c}{ Tratamientos } & Promedio & $\begin{array}{c}\text { Coeficiente de } \\
\text { variación }(\%)\end{array}$ \\
\hline $\begin{array}{l}\text { T1: Vacas con suplemento mineral orgánico } \\
\text { (células somáticas } / \mathrm{ml})\end{array}$ & $267,500 \pm 72,792^{\mathrm{a}}$ & 27,21 \\
T2: Vacas control (células somáticas $/ \mathrm{ml})$ & $391,000 \pm 296,285^{\mathrm{a}}$ & 75,76 \\
\hline
\end{tabular}

${ }^{a}$ Letras iguales significa que no existe diferencia estadística significativa.

${ }^{\mathrm{b}}$ Letras iguales significa que no existe diferencia estadística significativa.

valor inicial de $2,52 \%$ al día 80 , siguió incrementándose llegando a $2,68 \%$ en el día 87 , luego de este periodo tuvo una disminución que llegó a 2,58 \% para, finalmente, volver a subir hasta alcanzar un valor máximo de $282 \%$ al día 101 de lactación.

Esta diferencia evidente en la curva del tratamiento experimentalpudodebersetambiénaquelosmicroelementos del suplemento mineral orgánico cumplieron su función como cofactores, en el funcionamiento eficiente de los sistemas enzimáticos encargados de la síntesis de proteína, aún estando en la etapa final de la lactación en donde se presenta normalmente una disminución en el porcentaje de proteína.

Efecto de la suplementación mineral sobre el conteo de células somáticas

En la Tabla 11 se presentan los valores promedio del conteo de células somáticas en la leche de vacas de los tratamientos en evaluación.

Los resultados indican que para el caso de las vacas del grupo experimental se encontró un promedio de 267.500 células somáticas $/ \mathrm{ml}$ de leche versus 391.000 células somáticas $/ \mathrm{ml}$ encontradas para los animales del grupo control, notándose que existe una diferencia numérica a favor del grupo experimental, aunque no exista una diferencia estadística significativa. Este resultado permite asumir que hay un efecto de los minerales, en especial del zinc y el selenio, los cuales juegan un papel muy importante en el sistema inmunológico por medio de la activación de los linfocitos T, impactando así en una disminución del nivel de células somáticas dentro de la glándula mamaria. Asimismo, un modo de acción adicional del zinc es que tiene un efecto importante en la reducción del conteo de células somáticas debido a su rol de manera conjunta con el cobre, en la composición de la queratina del canal del pezón, formando una barrera de protección evitando el ingreso de microorganismos a la glándula mamaria.

Es importante mencionar que una reducción del 31,58\% (de 391.000 a 267.500 células somáticas/ml), en el nivel de células somáticas de la leche, tiene un importante impacto para el productor ya que actualmente la industria da una bonificación económica por la calidad de la leche, la misma que se basa en el conteo de células somáticas, es decir, cuanto más bajo es el nivel de células somáticas, mejor es la calidad de la leche.

Un motivo adicional por el cual el conteo de células somáticas es importante es su relación con los porcentajes de pérdida en la producción de leche, pues a mayor número de células somáticas, mayor porcentaje de pérdida. En la presente investigación tenemos un valor de 391.000 células somáticas/ml para el tratamiento testigo, del que podemos calcular una pérdida aproximada de $9 \%$ en la producción de leche.

En este sentido, los resultados obtenidos en el presente estudio deben ser tomados en cuenta por los ganaderos para mejorar la calidad de la leche producida y evitar pérdidas en la producción.

Los resultados obtenidos en el presente estudio coinciden con otros trabajos realizados con minerales orgánicos, como los de Kellogg et al. (2004) y Nocek et al. (2006). Los indicados autores determinaron que las vacas que consumieron niveles de 360 a $400 \mathrm{mg} /$ animal de zinc orgánico redujeron el recuento de células somáticas hasta 42,6\%, pasando de 298.000 a 171.000 células/ml.

\section{Conclusiones}

Se concluye que no existe efecto significativo del suplemento mineral orgánico sobre la producción de leche, el porcentaje de grasa y el conteo de células somáticas de la leche, sin embargo se registró un efecto significativo sobre el porcentaje de proteína en esta. Adicionalmente, si bien es cierto que no se encontraron diferencias significativas en el recuento de células somáticas en la leche, la existencia de una diferencia numérica, sin embargo, debe ser tomada en cuenta para mejorar la calidad de la leche ya que la industria genera una bonificación económica por este concepto.

\section{Literatura citada}

Calzada, J. 1981. Métodos estadísticos para la investigación. (4ta. edición). Perú.

Instituto Nacional de Defensa de la Competencia y de la Protección de la Propiedad Intelectual [INDECOPI] 1998. Normas técnicas del INDECOPI. Lima, Perú: INDECOPI.

Kellogg, D.; Tomlinson, D.; Socha, M. y Johnson, A. 2004. Effects of zinc methionine complex on milk production and somatic cell count of dairy cows: Twelvetrial. The professional animal scientist.

Nocek, J.; Socha, M. y Tomlinson, D. 2006. The Effect of Trace Mineral Fortification Level and Source on Performance of Dairy Cattle. Journal of Dairy Science, 89: 2679-2693

Uchida, K.; Mandebvu, P.; Ballard, C.; Sniffen, C. y Carter, M. 2001. Effect of Feeding a Combination of Zinc, Manganese and Copper Aminoacid Complexes and Cobalt Glucoheptonate on Performance of Early Lactation High Producing Dairy Cows. Animal Feed Science and Technology, 93: 193-203. 